\title{
Femoral implant applied on the lateral cortex of the femoral shaft
}

\section{Yves Cirotteau* \\ Neuilly Sur Seine Hospital, Courbevoie, France}

\section{Introduction}

In the report of an extensive analysis concerning a continuous series of 330 Total Hip Prosthesis of J. Charnley implanted by the same surgeon between July 1970 et April 1972, the follow-up is over 35 years. On the 12 patients still alive, (15 chips) $8 \%$ had a loosening of their femoral component and $8 \%$ of these undergo femoral loosening $[1,2]$.

The present report describes an original conception of a femoral component in a total hip prosthesis. The component is applied upon the lateral cortex of the femoral shaft. It is screwed on it by the mean of a plate.

The concept of this implant tries to reach as close as possible the natural physiology of a long bone during life [2-7]. The purpose is to gain a better longevity and consequently its utilization to young patients for whom a THP is the only solution.

Since November 1962 the Charnley hip replacement became rightly the gold standard for treatment of many orthopedic disease of the hip joint [7-13]. Actually, no one could dispute the merits of this affirmation, but in the same time, the question is: what is the coming up of these prostheses later? Which means: is it possible to operate a patient whatever his age without the fear of re-intervention later? Today, patients become very demanding.

According to the work of the University of Iowa and Des Moines Orthopedic Surgeons, after 35 years of follow-up, the percentage of femoral component loosening is hundred per cent for the patient who undergoes an operation to avoid definitely such loosening of the femoral stem, we set the component on the lateral femoral cortex [14]. With a 30 years retrospective follow-up, no loosening happens even when fixed in young patients (14 years). This is, according to our experience, the only way to keep in place the implant all lifelong.

\section{Material and methods}

Since 1982, the same operator has operated 85 patients. The youngest was 14een years old and the oldest was 50 . Most of them where women. The youngest had congenital either hip dysplasia, or complication of the Legg, Perthes, Calve disease, or acute laminar colitis of a hip epiphysiolysis. Other patients under rule a coxarthrosis whatever the cause (either traumatism such as hip luxation, femoral neck fracture, acetabular fracture, or they were overweight etc.). The management of the acetabulum was always a cemented Charnley polyethylene acetabular cup with a 22,2 diameter of the head.

The first femoral component (Figure 1) was in chrome-cobalt alloy so as the screws. Later on, it was in Titanium which is lighter. The diameter of the screw to maintain the greater trochanter was first fixed with a simple $5 \mathrm{~mm}$ screw but the design was have changed after some broken complications as it will be shown later.

\section{Philosophy and justification of the process}

The Charnley femoral component is fit in the femoral medullary canal, and in doing so, it destroys all the bone marrow and the cells it contains. Secondly, 2/3 of the internal part of the diaphyseal cortex of a long bone is vascularized by vessels coming from the intramedullary arterial system (Figures 2 and 3), as shown here, and 1/3 from the muscles surrounding the diaphysis.

A bone well vascularized should stay alive longer than a necrotic bone, even if some vessels coming from the periosteum will supply the deficient vessels. A young boy or girl will use (and abuse) his or her limb as often and much as he or she wants, keeping in mind that

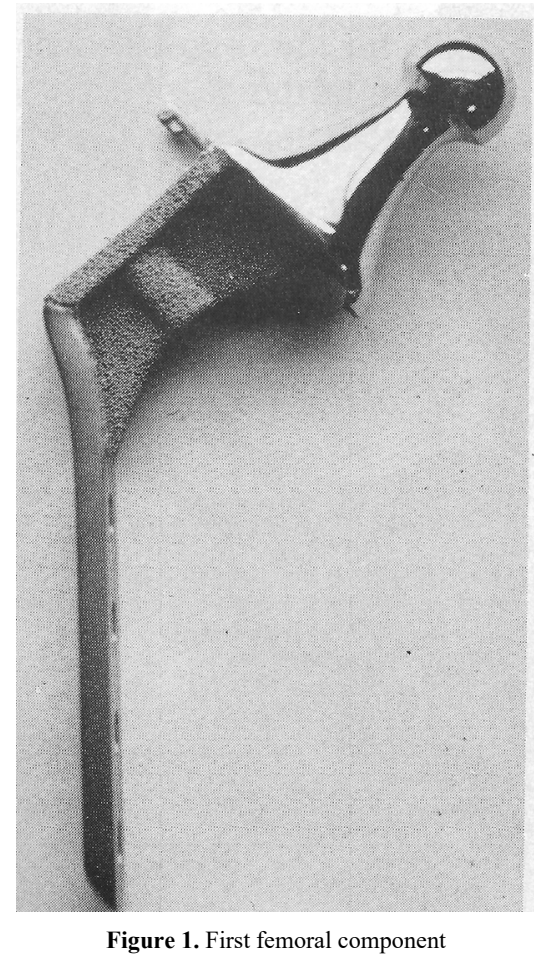

${ }^{\star}$ Correspondence to: Yves Cirotteau, Neuilly Sur Seine Hospital, Courbevoie, France, Tel: +33O621888265; Email: ciroto@club-internet.fr

Received: May 10, 2019; Accepted: May 28, 2019; Published: May 31, 2019 


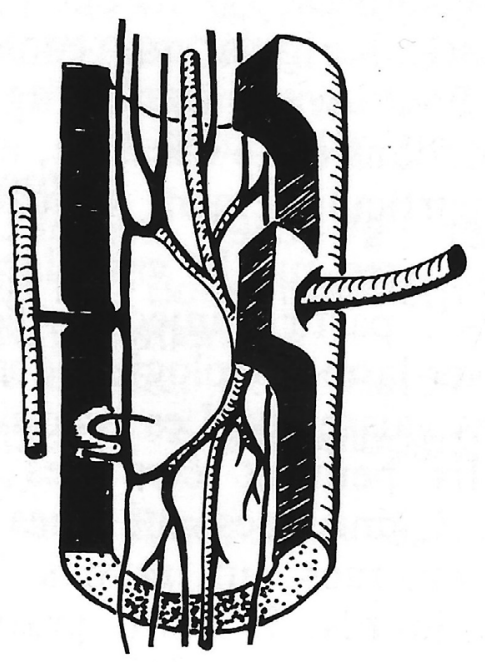

Figure 2. Endosteal and cortical capillaries network

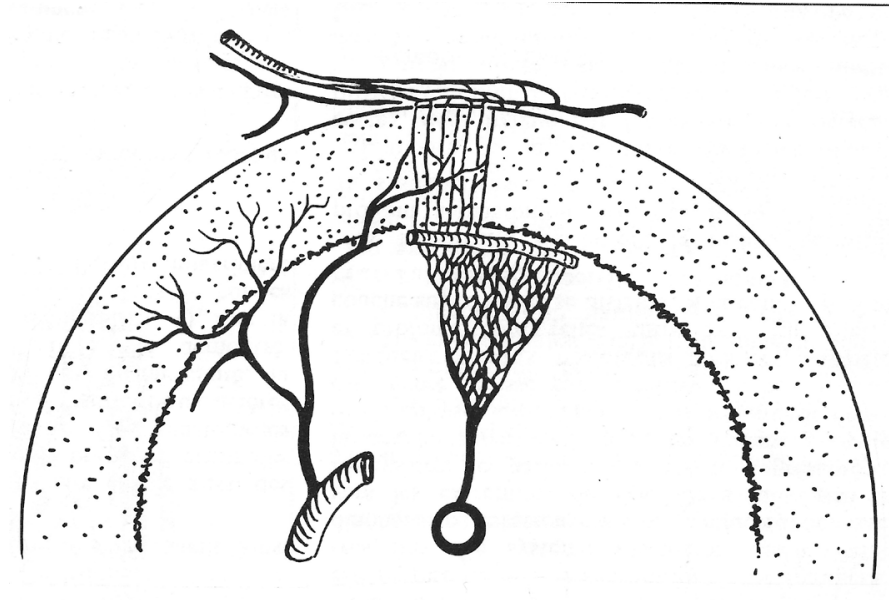

Figure 3. 1/3 from the muscles surrounding the diaphysis

the periosteum system is closed during muscle contraction! What will happen after years and years of such a situation?

The third point relates to the elasticity of the bone. Most of it is due to the metaphyseal cancellous bone. The intramedullary stem destroys it almost completely. Adversingly, the lateral fixation of the stem keeps the maximum of it alive, as shown here (Figure 4).

The fourth important point is the periosteum capacity to produce new bone all life long, even after 100 years [5-7]. Why do not try to use this possibility? Day after day, the bone layers will recover the plate so that the mechanical fixation will become stronger and stronger by time until death.

The fifth point is the Calmar resorption. Due to lack of support on the femoral calcar, a bone resorption happens by time. The large collar perfectly apply on the greater trochanteric cut restores pressure and no more resorption is seen as it was analysed $[8,9]$.

\section{External cortical femoral implant fixation}

I - Everyone, in his practice, had patients with more or less severe brain dysfunction. One of it is hemiplegia. What happens for the patient from an orthopedic point of view, on the lower limb? The reduced use reduces the pressure on the bearing bone and, from a physiological point of view, a reduction of the mineralization. The bone becomes osteoporotic. This physical phenomenon is reversible when the pressure conditions are restored. Her are two examples this patient had a right hemorrhagic stroke few years ago (Figure 5a). He had a left hemiplegia and spent a long time in physiotherapy due to the difficulty to walk. Note the thin both femoral cortical due to the bad utilisation of the left lower limb. Few years later, he recovered a best walking. Note the very good thickening due to the best support of his body weight by the limb (Figure 5b).

(Figure 6) Despite the severe coxarthrosis note the good thickness of the femoral cortex before the operation.

(Figure 6a-b) Few years later the patient had a hemiplegia. Note the increasing diameter of the femoral medullary canal (Figure 6c). What would have happened if an intramedullary implant was set in it?

Note the periosteum layers covering the extremity of the plate, fixing it strongly to the femoral cortex (Figures 7 and 8).

There is no resorption of the calcar. Neck femoral component lies perfectly on the trochanteric osteotomy 30 years after implantation (Figure 9 and 10).

\section{Mechanical complication}

Is there any mechanical complications such as: broken screws or broken plates? Yes, in a very small cases, some screws fixing the greater trochanter broke. If the osteotomy of this apophysis is consolidated, nothing will happen (Figure 11). In some case the lateral part of the broken screws must be removed when painful. When the results of fourteenth femoral implantations were shown with 4 years followup some surgeon ironically assessed that imagination and originality deserves that attention, which the searcher appreciates (Figure 12). But few minutes after claims that Dr Cirotteau, had neither the follow-up nor the sufficient number which was, in his eyes, the most scientifically important fact and, added he vehemently, screws are working on pull
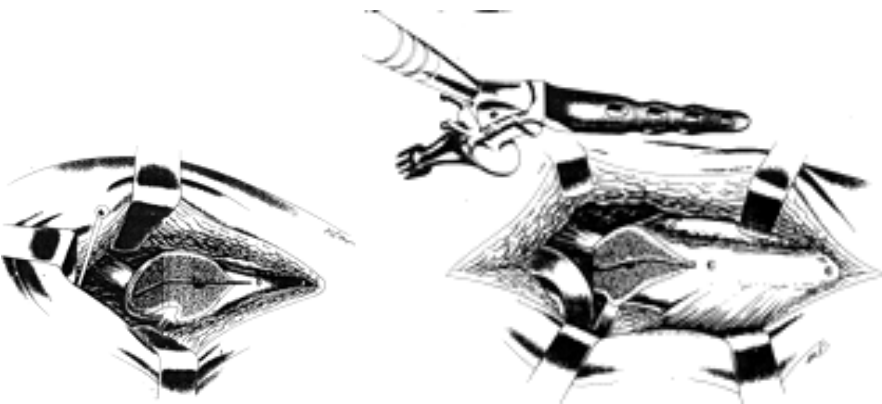

Figure 4. Lateral fixation of the stem
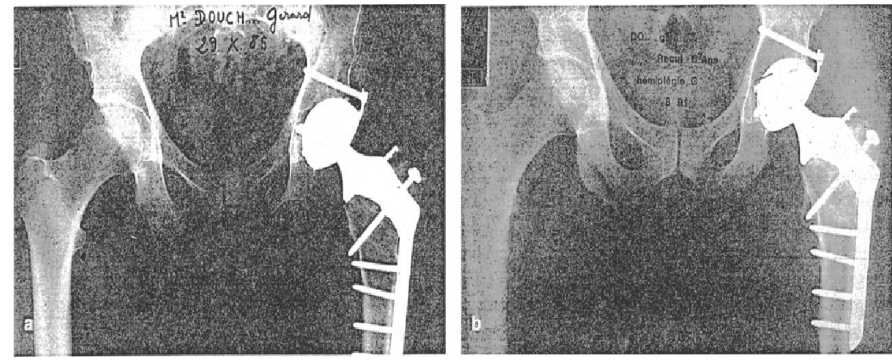

Figure 5. (A) the thin cortical (B) Note the beautiful reconstruction 


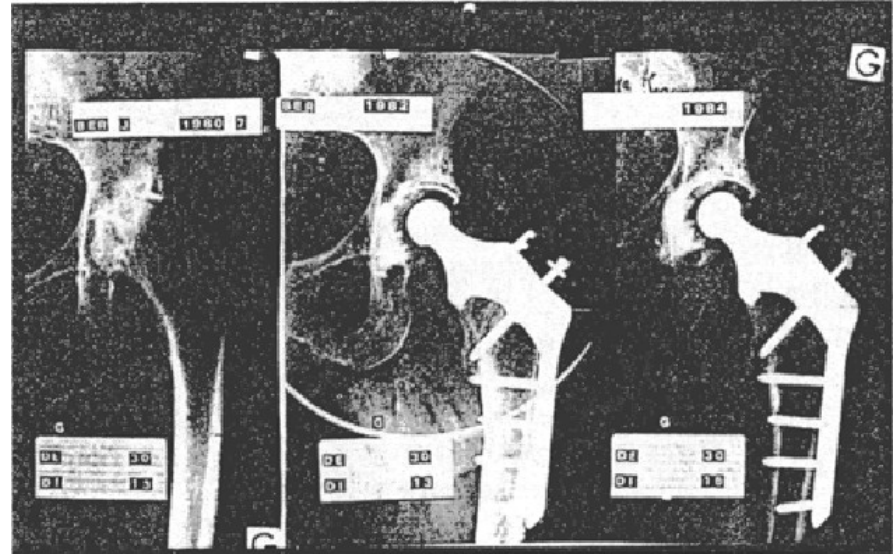

Figure 6. Good thickness of the femoral cortex before the operation
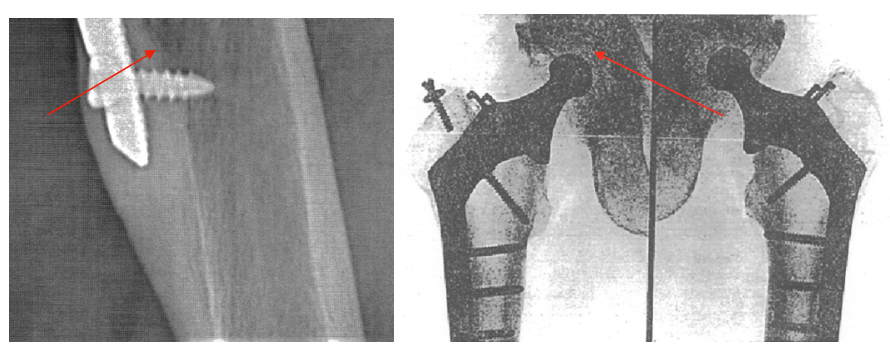

Figure 7. Lateral part of broken screws

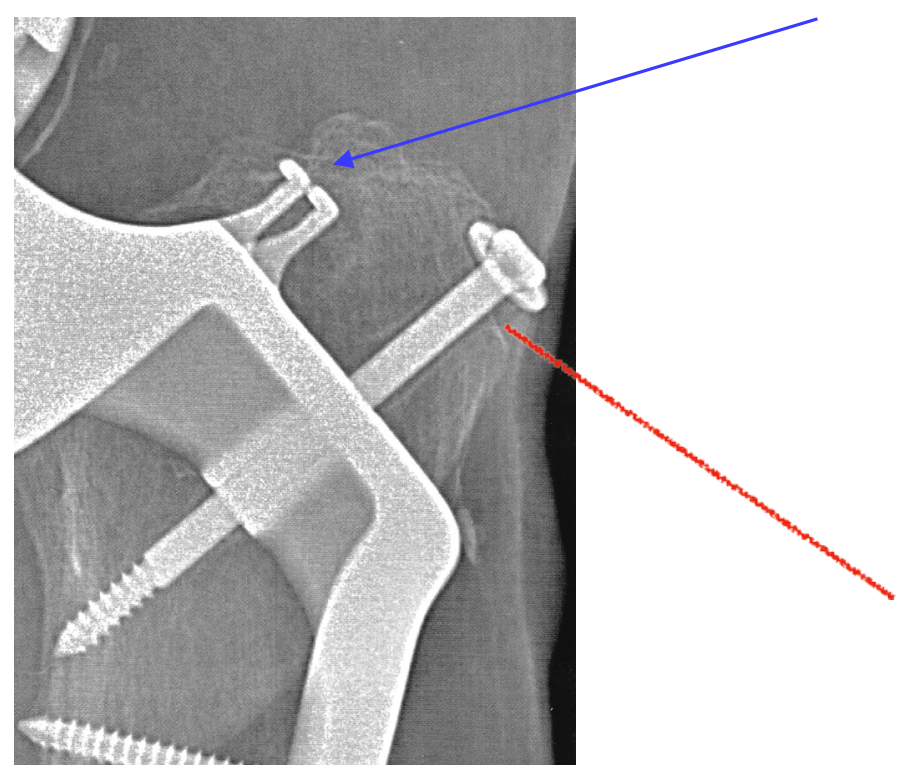

Figure 8. Design of the screw, increasing the diameter $(6 \mathrm{mms})$ and changing its soul. In blue, teeth-like, in red, screw soul

out and there solidity on a sure long term fixation in an ageing bone looks in certain, despite the theoretic justifications attempts of the author. Most probably, this attractive surgeon totally mocks the bone physiology, unless he does not know it (Figure 13).

Note the fracture of both $5 \mathrm{~mm}$ diameter trochanterical screws. Despite it, both greater trochanter are anatomically in the place. Note the new bone apposition along the upper part of the femoral shaft fixing mechanically both apophysis (red arrows). Note equally both teeth-like whose the purpose is to decrease the gluteus medius pulling (Blue arrow). We have modified the design of this screw, increasing the diameter (6 mms) and changing its soul. In blue, teeth-like, in red, screw soul.

\section{Technical procedure}

At the beginning, all Charnley's cup, 22,2 $\mathrm{mmm}$ diameter of the head on the left side were cemented. The insert is in polyethylene. Later one, it was a non-cemented metal back acetabulum, with a 22,2 diameter of the head. Insert was in polyethylene.

Lateral femoral implant is in titanium on both sides. The screws were of $5 \mathrm{~mm}$ of diameter for the femoral shaft, and $6 \mathrm{~mm}$ of diameter to fix the greater trochanter.

\section{Clinical examination}

This patient was seen in an office in May 2019. Follow up: 30 years on the left side, Follow up: 26 years on the right side. She had no pain. She can climb stairs up and down without difficulty. Over three floors, she uses the ramp stairs. She walks without help as long as she

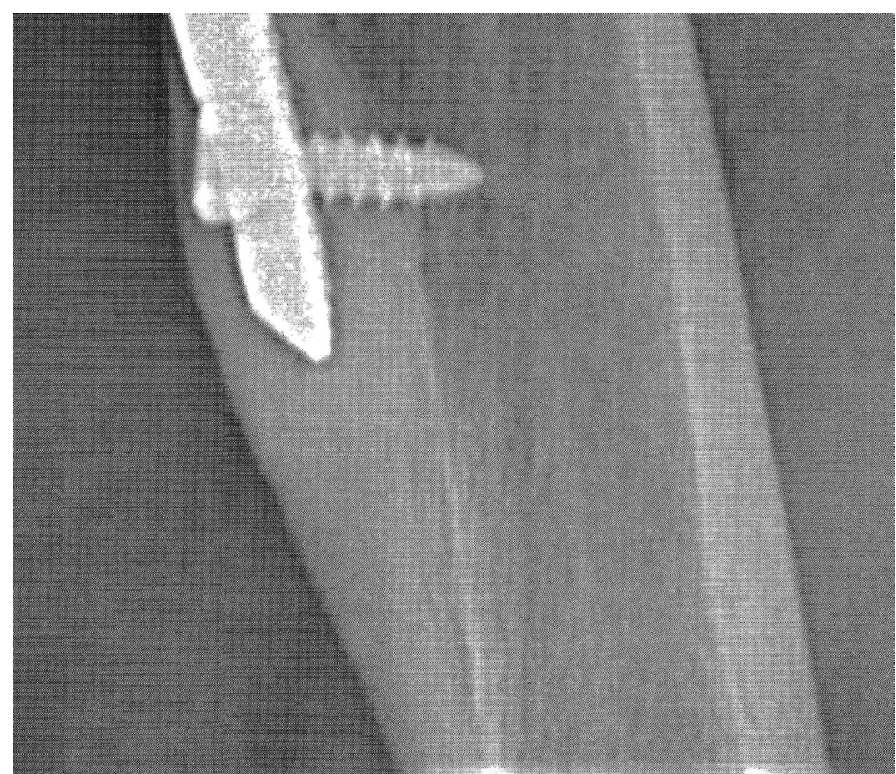

Figure 9. Periosteum layers covering the extremity of the plate

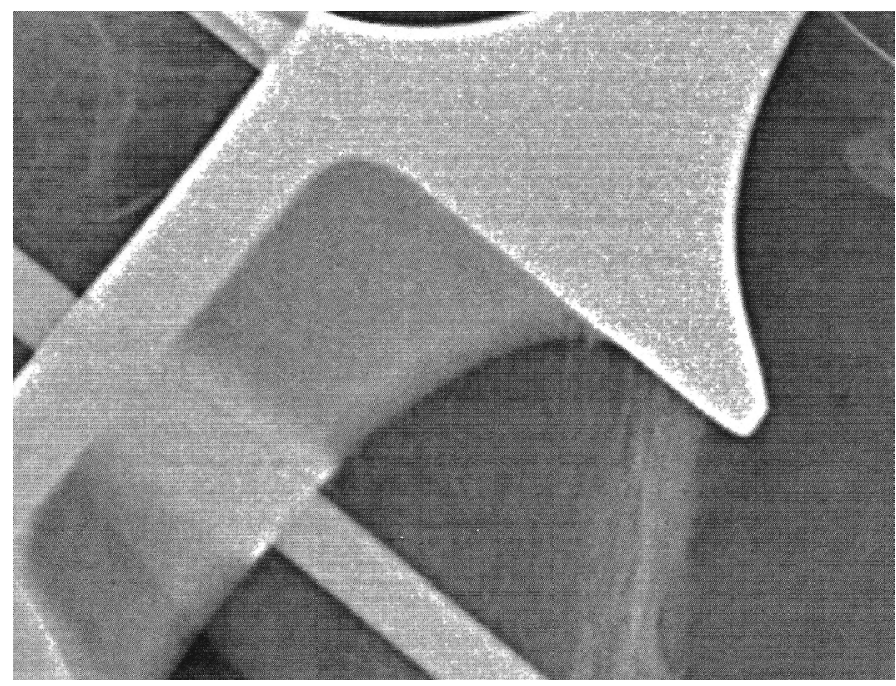

Figure 10. Neck femoral component lies perfectly on the trochanteric osteotomy 30 years after implantation 


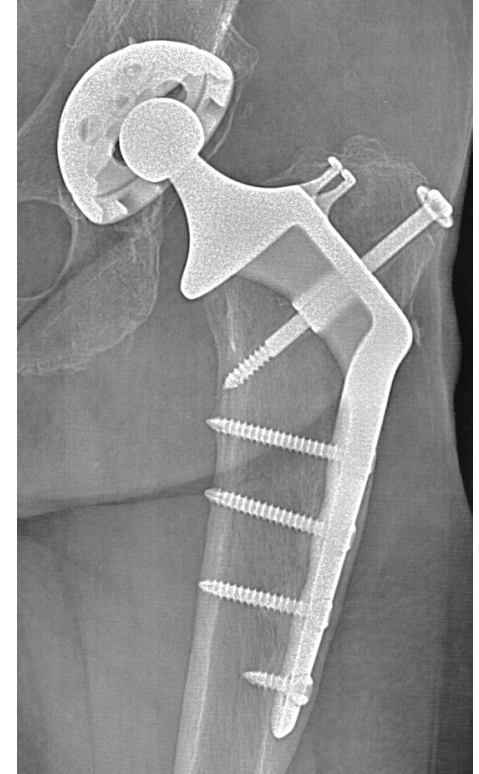

Figure 11. The design of the plate and screws were copied according to the Muller's screw design

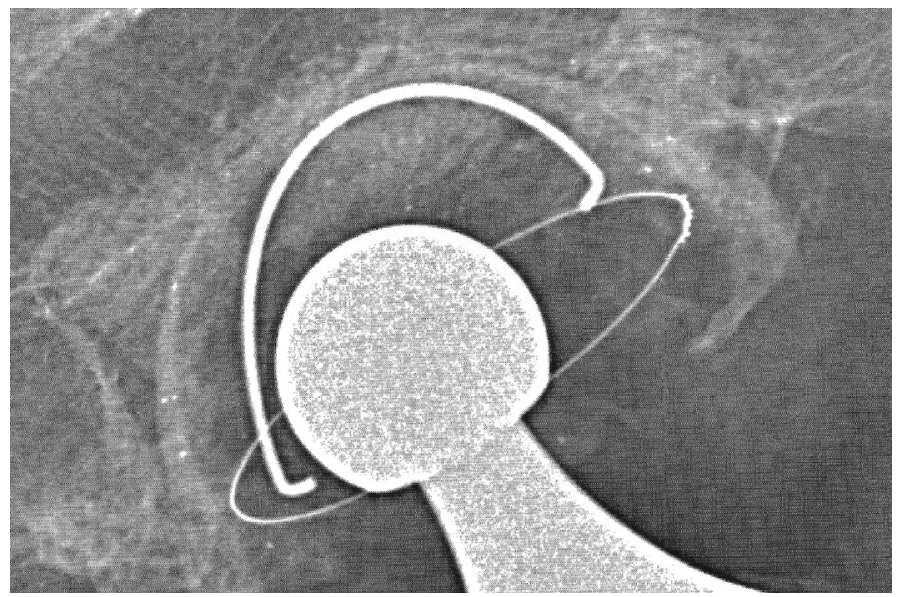

Figure 12. Moderate wear of the acetabulum cup polyethylene

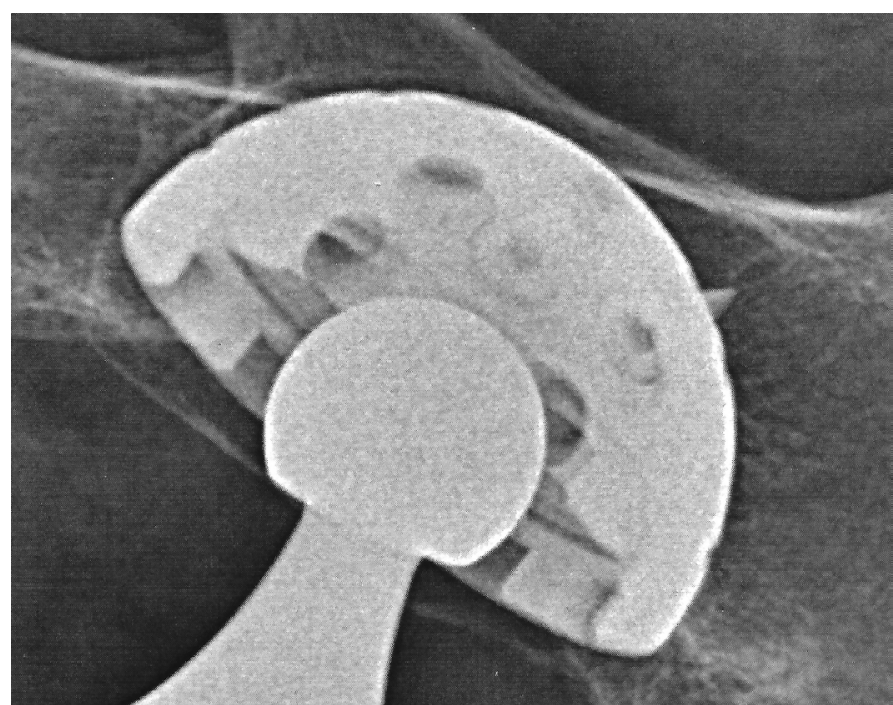

Figure 13. No wear of polyethylene cup wants, one hour without stop. She walks without limping. PM: One hour, without stop in a quiet walk. She has a normal life. She pratices sports Tai chi twice a week, one hour with other members. She goes in hollydays either in Canaries, Grece, or in the mountains Pyrénées, or Saint Jean de luz. She is a grand-ma sitter every sunday. She plays piano, sings in a chorus opera, and has a lot of additional activities. Mobility of the Left hip: 1400 - 3520 - 20 20. Right hip: 1400 - 4040 - 3020 .

\section{Functional scores} Good.

Postel-Merle Aubigné (PMA) Pain, mobility, walking 4 grades:

Harris hip score: Bread, Function, Mobility, No deformity Score from 100: 90-100: excellent.

Oxford hip score: Activities of daily living. Self-administered 12item questionnaire administered a score: $42-48$ : which is excellent.

\section{$\mathrm{X}$ rays}

The design of the plate and screws were copied according to the Muller's screw design.

\section{Discussion}

The first planning was to start with a well-considered definition. The goal expected was to secure the femoral implant on its support so that it would stay all day long, as long as patient's life. The second question was followed by the development of an effective strategy. Once establishing the goal and the strategy, do the searcher has worked backwards to identify the next steps? Has he reached the goal expected? How can be sure that the femoral implant will be aware of complications in $100 \%$. In fact, one must must answer to three questions:

- Was the bone physiology respected? The answer is yes concerning the cancellous bone, the femoral cortices, the role of the periosteum. There was not any calcar resorption.

- Did any mechanical complications such as: broken screws or broken plates happened? Yes, in a very small cases, some screws fixing the greater trochanter broke. If the osteotomy of this apophysis is consolidated, nothing will happen as seen. In some case the lateral part of the broken screws had to removed when or if painful. Since the design of the screws was modified, ( $6 \mathrm{~mm}$ of diameter) no one broke.

- The goal was it reached? According to the results, the answer is yes. None of the plate was removed. All patients are to Day either too old or are in a very high place in the sky where I cannot reach them or are still living with their implants.

Now, everyone should use their small grey cells as Hercule Poirot does. Let us be imaginative and put ourselves in the shoes of a long bone such as a femur, for example. I am (was) a happy femur. All my vessels are in a good shape. My intra medullary canal artery is surrounded by the soft bone marrow and both are well protected by the strong wall of my cortices. We both play a critical physiological role. I give the vascularisation at the $2 / 3$ media part of my walls, and the bone marrow in my canal gives to all cells necessaries for their maintenance. The $1 / 3$ of the lateral part of my fortress is vascularised by some big muscles whose small vessels go horizontally through the periosteum. Sometimes, I feel cold because these vessels collapse when a physical effort constricts the muscles of the thigh. The muscle contraction interrupts the blood flow. It is as if this part of my bone was dead during this effort. Suddenly, inopportunely, something very hard and rough enters my house canal and destroys all the furnitures, leaving only walls, ruin and desolation. 
The icing on the cake is that, when after days of recovery, I try to run again, the last portion of the wall left intact by vandals collapses also my muscular vessels. How long would and could I endure such a desperate situation?

\section{Conclusion}

The lateral femoral implant is one of the good solutions for a long implant femoral life, as long as the patient's life, whatever his age. But the searcher should stress on the difficulty of its fixation on the upper femoral metaphysis. The greater trochanteric osteotomy must be perfectly done. The screws must be of a good size and length. We must respect the consolidation delay of this bone section and periosteal fixation. The patient must walk with two crutches during this time with only a contact support. At least 2 or 3 months according to the XR. Just keep in mind that the choice is 3 months inconvenience against a life of freedom.

A surgeon is not at all a simple fucking operating machine. He must practice with his heart and must explain to his patient what he will do, why he will do it, and what his patient must do or not do. That is the price to pay.

\section{References}

1. Callaghan JJ, Bracha P, Liu SS, Piyaworakhun S, Goetz DD, et al. (2009) Survivorship of a charnley total hip arthroplasty: a concise follow-up, at a minimum of thirty-five years, of previous reports. J Bone Joint Surg Am 91: 2617-2621.
2. Theo L, Vidal J, Dossa J (1989) Bone tissue coll. biology of the locomotor apparatus. Sauramps medical 67-74.

3. Cirotteau Y, Kerboull M (2009) Morphological modifications of a long bone diaphysis in adult. Theoretical therapeutic deductions. The Surgical Letter 128.

4. Chapter M (2009) History of the total hip arthroplasty in France. Rhumatologie Pratique 3: 5-7.

5. Cirotteau Y (1999) Morphological modifications of the upper femoral metaphysis in an osteoporotic patient. French Science Academy III.

6. Rouviere H (1954) Human Anatomy, seventh revised edition by Cordier G Tome III, 263 Masson, Paris.

7. Dumbleton JH, Buschelow M (1990) A Strain Gage Analysis of the Cirotteau Hip Prothesis Howmedica: Divisional Research and Development. Rutherford - USA.

8. Cirotteau Y, Pelisse F (1990) Notes on the conclusions of the study done by the society Howmedica concerning the Hip prothesis. C.I.A.V. Les Charmilles. Valenton - France.

9. Cirotteau Y (1985) The hip Implants with a lateral cortical fixation. Annals of the Academy of Surgery III: 817-823.

10. Cirotteau Y (1996) Femoral implant fixed on the lateral cortex: Long term follow-up in young patients with a coxarthrosis. European Journal of Orthopaedic Surgery and Traumatologie 6: 247-253.

11. Cirotteau Y (1989) Critic and results of the implant fixed on the lateral femoral shaft. Surgery 115: 373-379.

12. Cirotteau Y (1989) What is the interest of implant fixed on the femoral lateral cortex. Livret Information for patients Questions-Answers.

13. Cirotteau Y (1988) Femoral Cortical Implant. Surgery books 3: 67.

14. Ruedi TH, von Hochstetter, Schlumpf R (1984) Surgical Approaches for Internal Fixation, AHC. Springer Verlag.

Copyright: (C2019 Cirotteau Y. This is an open-access article distributed under the terms of the Creative Commons Attribution License, which permits unrestricted use, distribution, and reproduction in any medium, provided the original author and source are credited. 